\title{
DEN PARADOXALA FÅNGVÅRDEN OCH DESS DOLDA UPPGIFT
}

\author{
Av MERJA-LiISA HiNKKANEN-LIEVONEN
}

1. Under den senaste tiden har man ovanligt mycket diskuterat fångvården i Finland. Diskussionen inleddes sommaren 1987 med en tidningsartikel av en av fångvårdsavdelningens egna tjänstemän. Åsiktsutbytet fortgick livligt under flera månader.

Denna framställning har fått sitt byggnadsmaterial av den förda diskussionen och strävar efter att framföra vissa tankelekar och hypoteser om fångvårdens samhälleliga uppgift.

2. Målsättningarna för fångvården i Finland har i lagstiftningen fått följande utformning: straffet skall verkställas så att det ej i onödan försvårar utan i mån av möjlighet befrämjar fånges inpassning i samhället. De olägenheter, vilka frihetsförlusten förorsakar, skall i mån av möjlighet förhindras.

Förebyggandet av återfallsbrottslighet uppställs inte i sig självt som ett mål, utan man talar i försiktiga ordalag om fånges inpassning i samhället. I målsättningarna erkänner man däremot explicit, att verkställigheten av straff försvårar anpassningen $\mathrm{i}$ frihet.

Trots den försiktiga formuleringen av målsättningarna mäts fångvården i Finland, såsom fångvården i allmänhet, i offentligheten med återfallsbrottsligheten som mätare. Så skedde också under den debatt om fångvården som inleddes sommaren 1987. Debattens viktigaste tema var fångvårdens misslyckande. Många debattörer ansåg att återfallsbrottslighetens nivå utvisade graden av fångvårdens misslyckande.

I en artikel i landets största dagstidning konstaterades: „Fängelset har inte kunnat hjälpa fångarna, eftersom två av tre återkommer till fängelset«. (1) En professor i straffrätt var av samma åsikt: »Fängelseväsendet har inte lyckats $i$ sin uppgift att förebygga brottslighet «. (2)

Man kan dryfta påståendet att »återfallsbrottsligheten är ett tecken på att fångvården misslyckats« ur många synvinklar. Vi kunde t.ex. placera fångvården i sin verksamhetsomgivning och påpeka, att det inte är fråga om att bara fångvården misslyckats utan att hela samhället misslyckats. Många faktorer utanför fängelset inverkar ju på benägenheten att återfalla i brott: att få bostad och arbete, människorelationer eller brist på dem. Sett ur denna synvinkel är det därför oskäligt att lägga ansvaret för återfallsbrottsligheten enbart på fångvården. 
Ett annat sätt att förhålla sig skulle vara att medge att fångvården misslyckats, men förklara detta misslyckande med den inneliggande omöjlighet som ingår i fångvårdens uppgift. Denna omöjlighet kommer klart till uttryck i målsättningarna för fångvården i Finland: „De olägenheter, vilka frihetsförlusten förorsakar, skall $i$ mån av möjlighet förhindras«. Man förutsätter alltså att fångvården med ena handen skall beröva en människa hennes frihet och med den andra förhindra verkningarna av frihetsberövandet.

Denna fångvårdens inneboende paradox är enligt min mening det mest förvånansvärda draget $\mathrm{i}$ fångvården. En analog situation skulle vara, om arbetskraftsbyråerna först skulle beröva människorna deras arbetsplats och sedan betala dem arbetslöshetsersättning. Eller om en ambulansförares uppgift skulle vara att först köra på en människa och sedan såsom expert sörja för hennes eftervård.

Konflikten är enligt min mening så stor, att den sannolikt gör det omöjligt att uppnå de mål som explicit uppställts för fångvården. Med andra ord: Schizofrenin i fångvårdens organisation och målsättningar gör det även omöjligt att förebygga återfallsbrottslighet.

Den tredje synvinkeln för påståendet, att återfallsbrottsligheten är en mätare på hur misslyckad fångvården är, är likväl ännu mer intressant. Jag vill nämligen ifrågasätta hela påståendet. Egentligen vill jag ställa det på huvudet genom att anta, att återfallsbrottsligheten i själva verket mäter hur lyckad fångvården är. Jag vill påstå att producerandet av återfallsbrottslighet och inte att förebygga den är fångvårdens viktigaste uppgift i samhället. Och att den inbyggda paradoxen åtminstone är en av de mekanismer, genom vilken fångvården producerar återfallsbrottslighet.

Det är nämligen svårt att tro att det i samhället skulle kunna finnas en bestående och långvarig organisation sådan som fångvården, som likväl fortgående och på ett katastrofalt sätt misslyckas med en av sina centrala uppgifter. I fortsättningen uppställer jag därför som hypotes, att fångvården ingalunda är en institution, som misslyckas utan i själva verket en sällsynt och världsomfattande framgångsrik sådan. Jag skall dryfta, vilka slutledningar denna hypotes för oss till.

3. Vi antar alltså, att fångvårdens uppgift är att producera fångar för samhället. Fängelserna är produktionsinrättningar för återfallsförbrytare. Att på nytt hamna i fängelse är en slags fortbildnings- och handledningsperiod i denna långa produktionsprocess.

Fängelset har effekt på de flesta fångar: de blir kvar i branschen efter en effektiv grundutbildning och påbörjar sin karriär; från första resans fånge till andra resans, tredje-, tolfte resans. Det är heller inte svårt att avancera i detta system. Fängelsevistelserna tar bort de sista möjligheterna till arbete, bostad och människokontakter. I samhället kommer man inte riktigt till rätta utan dessa.

På detta sätt garanterar förhållandet mellan samhället och fängelset, eftervården, att en person som en gång slagit sig in på fångbranschen blir vid sin läst. Och in- 
genting ont med det, eftersom en återfallsförbrytare är fångvårdens mest förtjänstfulla produkt. Han har insett vad samhället väntar sig av honom.

De som av någon orsak inte återfaller i brott eller efter åratal i fängelse får grepp om det vanliga livet, är felinvesteringar ur fångproduktionens synvinkel, förträtliga flyktningar från ett nästan heltäckande system. De effektivaste sätten att komma bort från fångkarriären, »AA, käringen och religionen«, beskriver just genom sin slumpmässighet, sin individuella karaktär och sällsynthet att systemet är orubbligt och oföränderligt. Det går inte att undvika återfall i brott om inte högre krafter, Gud eller kärleken, blandar sig i spelet.

På toppen av sin karriär är fången märkt av sin framgång, liksom en verkställande direktör som av samhället fått en annan slags roll. Tecknena på framgång är bara annorlunda. På toppen är fången alkoholiserad, utbränd, åsidosatt, tegelbiten. Då har han utfört den uppgift ödet gav honom. En snabb karriär och ett dynamiskt fängelseliv har bränt slut på mannen alldeles på samma sätt som det dynamiska affärslivet gör.

4. Om detta verkade makabert, absurt och polemiskt, är det bra. Då kan vi genom att ta avstånd till fångens liv i fortsättningen på en något mer akademisk nivå dryfta,

a) för vilka ändamål man producerar fångar;

b) vilka är de mekanismer genom vilka fångvården producerar fångar; samt

c) varför och på vilket sätt man döljer produktionsmekanismerna och deras syfte.

Till en början lär det vara skäl att precisera vissa begrepp. »Producering av fångar « innebär inte, att fångvården medvetet och målinriktat försöker åstadkomma återfallsbrottslighet. Produceringen av fångar är med andra ord inte avsiktlig, utan det är fråga om en för fångvården i samhället utbildad dold uppgift, ett sätt på vilket en specifik samhällelig mekanism fungerar. En liknande uppgift har också t.ex. domstolsväsendet i lika stor utsträckning som fångvården.

För vilket ändamål behöver samhället fångar? Vi kan inleda med att söka orsakerna till produktionen av fångar från den kanske rätt allmänna synen, att samhället $\mathrm{i}$ anstalter stänger in personer som är oförmögna till »normal« verksamhet eller som inte anpassar sig till normer eller produktionslivet.

Enligt denna syn skulle samhällets kontroll få grepp om människan först då hon hamnar i fängelse. Analysen går dock djupare då vi märker, att samhället inte i anstalter stänger in endast »från det normala« avvikande individer, utan att man först producerar och väljer ut »avvikande« individer i en samhällelig process. Då en fånge anländer till fängelset har han redan fått en god start på sin karriär: han har redan gått igenom den förberedande förädlingsprocessen.

Jag skall i det följande presentera en, som jag anser, mycket intressant tolkning av definitionen på brottslighet. Denna förklaringsmodell har utformats av forskaren Raila Taipale. Följande korta referat kan tyvärr inte ge full rättvisa åt hennes mångsidiga analys. 
Utgångspunkten för tolkningen är, att ett samfund eller samhälle inte vill möta och igenkänna det onda i sig själv. Därför projicerar samfundet det onda på vissa individer som utvalts att bli bärare av det onda. Dessa individer som utvalts att bli avvikande är offer, som samfundet överlåter att på ett rituellt sätt dömas och bestraffas. Offren bär på det onda i hela samhällets namn för att samfundet kan renas.

På detta sätt producerar samfundet alltså avvikande beteende. Samhällskontrollen tar människan i sitt våld genom en urvals- och processeringskedja för avvikande beteende, som börjar redan i barndomen. Lekplatser, daghem och skolor är platser, där utbildade experter fungerar som representanter för samhällskontrollen: lärare, barnträdgårdslärare, barnskötare. De håller ögonen öppna efter eventuella tecken på det onda i barnen.

Man lägger nogsamt märke till tidiga uttryck för potentiellt avvikande beteende och ställer upp gränser för det, genom vilket man skapar reaktioner mot gränserna. Dessa reaktioner tolkas som nya tecken på avvikande beteende. Reaktioner inför gränserna leder till nya begränsningar och till stigmatisering av den som reagerar. På detta sätt fortsätter processen tills det onda har isolerats, dömts och sänts till fängelse. (3)

5. I det följande diskuteras frågan om fångproduktionens mekanismer. För att fångvården skall lyckas med att producera återfallsbrottslingar, bör produktionsmekanismen troligtvis vara inbyggd i fångvården för att garantera bästa möjliga funktion. Därför är det logiskt att anta, att fångvårdens paradox, dess inbyggda konflikt, är det centrala instrumentet i produktionen av återfallsbrottslighet. Jag skall därför i fortsättningen koncentrera mig på att dryfta fångvårdens paradox ur olika synvinklar.

Fångvårdens paradox innebär en intern konflikt, en dualism, en motsättning mellan två delar. Det verkar likväl som om en förutsättning för att konflikten skall fungera skulle vara en viss enhetlighet: det att fångvården, såväl dess »inlåsande« som »rehabiliterande« del, är i händerna på en och samma myndighet. På detta sätt garanteras kontrollens och systemets fasthet. Om skilda myndigheter skulle sörja för frihetsberövandet och rehabiliteringen, skulle fångvårdens konflikt få en annorlunda skepnad - det kunde uppstå en verklig konflikt mellan de »rehabiliterande« och »inlåsande « myndigheterna, en kamp om reviret, och utgången i denna kamp kunde vara osäker.

Då den interna konflikten lever inom en myndighetsorganisations verksamhet uppstår det lätt en bild, att balansen eller preferensordningen mellan de olika delarna av konflikten, mellan frihetsberövandet och förebyggandet av dess skadliga verkningar, är det centrala. Ett exempel på denna syn är den diskussion som förts om fångvårdens nuläge i Finland.

Den viktigaste kritiken som framförts under diskussionen är, att förverkligandet 
av den stora fångvårdsreformen från år 1975 har lämnats på hälft. Man klandrade fångvården för brist på reformvilja och stagnation i gamla attityder.

Jag skall i det följande citera en tidningsartikel av den centrala kritikern, den tjänsteman som nämndes i början av mitt anförande. Den tankemässiga grunden för kritiken utgick från, att det traditionella anstaltstänkandet nu håller på att brytas ner bl.a. inom åldrings- och sinnessjukvården. Enligt författaren hade 1975 års fångvårdsreform samma målsättning. Dess mål var att förändra anstaltslivet till en meningsfull helhet, vars positiva verkan skulle grunda sig t.ex. på meningsfullt arbete och yrkesutbildning och på rehabiliterande funktioner. Förverkligandet av fångvårdsreformen är dock ännu på hälft, vilket enligt författaren bl.a. tar sig uttryck i social- och rehabiliteringsservicens anspråkslösa nivå i fängelserna samt i en överbetoning av bevakningen och kontrollen i anstaltslivet. Bevakningen är fortfarande den viktigaste funktionen i fängelserna. Man har inte gjort allt som man skulle ha kunnat för att göra fångarnas liv innehållsrikare och som enligt lagstiftningen även borde göras. Författaren talar om den finska fångvårdens »snedvridna linje«, i vilken »människocentrerade strävanden hamnar i fötterna på förvaringsideologin«. (4)

Det skulle vara fruktbart att undersöka substansen i kritiken: är situationen denna och varför? Min avsikt är likväl att bedöma den framförda kritiken utgående från fångvårdens paradox; såsom ett försök att förklara fångvårdens interna konflikt. Man söker ofta en lösning på denna konflikt genom att betona den sida av fångvården, som syftar till att rehabilitera fången och till att förbereda honom för frigivningen.

6. Den väsentliga premissen i den framförda kritiken är, att fångvården och dess målsättningar i dag är annorlunda än tidigare. Detta framgår av följande citat:

»Fängelsernas existens motiveras inte längre med, att man i dem $i$ sedligt avseende kan »förbättra« fångarna, göra laglydiga medborgare av dem«. Så var det förr. Enligt författaren är målsättningen för fångvården i dag att anpassa fången i samhället genom att $\mathrm{i}$ anstalten förbättra hans bristfälliga möjligheter att klara sig. »Man vill hjälpa fången att klara sig i frihet utan brott, men man försöker inte längre genom uppfostran omvända honom till en sk. ordentlig människa«. (4)

Infallsvinkeln är intressant. Enligt den är skillnaden mellan det förgångna och nutiden den, att man tidigare ville påverka fången mot hans egen vilja, man försökte omvända honom. I dag skulle det däremot endast vara fråga om att hjälpa honom, vilket implicerar att målsättningen för hjälpen, anpassning i samhället, även skulle vara vad fången själv vill.

Det är skäl att ifrågasätta påståendet. Är anpassning i samhället i själva verket fångens egen vilja? Varför antar man att så är fallet? Vad händer om en fånge i fängelset meddelar att han också i fortsättningen tänker begå brott? Blir personalen frustrerad? Eller hur förhåller sig eftervården om en frigiven fånge vill använda sig av Kriminalvårdsföreningens härbärge som bas för sin illegala verksamhet? 
Denna tankelek leder till många slutsatser. En av dem beskriver det kanske centrala sättet att producera återfallsbrottslingar. Fångvårdens paradox producerar recidivister på så sätt, att man uppställer ett omöjligt mål för fången: han måste lyckas i friheten. Denna trollcirkel av försök och misslyckande som bryter ner självförtroendet håller kvar fången som en recidivist. Om återfall i brott däremot är fångens medvetna mål, nekar han i själva verket att spela enligt spelets regler. Han ifrågasätter hela fångvårdsspelet genom att göra den dolda uppgift, som samhället har anvisat honom, till sitt eget frivilliga val. Samhället bör alltså kunna kontrollera inte enbart rekryteringen av fångar utan också valmekanismerna i recidivistens karriär.

Ett annat spörsmål som betonar kontrollens centrala ställning även i dagens fångvård är, att man koncentrerar sig just på att hjälpa fången. Logiskt tänkt är detta egentligen underligt - hur fången klarar sig i friheten beror ju endast till en del på honom själv. Lika väl kunde man tänka sig, att i stället för kurser som förbereder fången för arbetslivet och utbildning skulle man i internat anordna omskolningskurser för arbetsgivare, för att dessa skulle bli sådana samhällsdugliga medborgare som skulle ge arbete åt föredetta fångar. I dag anpassas fången i stället för att samhället skulle anpassa sig.

Den tredje iakttagelsen: När man talar om att hjälpa fången kamouflerar detta kontrollen - m.a.o. kritikens premiss om fångvårdens ändrade målsättningar är felaktig. Enligt citatet försökte man tidigare i fängelserna »i sedligt avseende »förbättra« fångarna, göra laglydiga medborgare av dem«. Nuförtiden däremot vill man »hjälpa fången att klara sig $i$ frihet utan brott, men man försöker inte längre genom uppfostran omvända honom till en sk. ordentlig människa«.

Enligt min mening har det inte skett någon förändring i denna sak. Om man »vill hjälpa fången att klara sig i frihet utan brott, är det i själva verket fråga om, att man »vill hjälpa« fången att bli en laglydig medborgare. En verklig förändring inom fångvården skulle ske först när fångvården inte skulle ha några som helst målsättningar beträffande en fånges liv efter det han frigivits.

Kontrollen finns med andra ord fortfarande till, avsikten är fortfarande att förändra fången. Nuförtiden har man endast gjort termerna mjukare, mer dolda än tidigare. Man talar hellre om »klienter« eller »intagna« än om »fångar«. Man använder eufemismer vilkas syfte är att kamouflera kontrollen och produktionen av pina.

Fångvården i samtliga nordiska länder har sina egna eufemistiska fraser. Ett exempel på kamoufleringen av kontrollen är de uttalade målsättningarna för fångvården i Sverige. Detta avslöjar spänningen mellan de två huvudmålsättningarna för Sveriges fångvård: "Att genom stödjande insatser medverkar till deras (de dömda) rehabilitering eller anpassning i samhället « och å andra sidan »Att så långt det är möjligt hindra dem från att begå nya brott«. Den senare målsättningen, att förhindra återfallsbrottslighet, kan endast förverkligas genom den första målsättningen, dvs. genom att stöda fångarnas anpassning i samhället. 
Fångvårdens paradox är alltså inte ensidig. Frågan är inte enbart, att man å ena sidan borde straffa och å andra sidan hjälpa. Frågan gäller även en humanistisk, utvecklingsoptimistisk och mer dold paradox, på vilken jag som exempel tagit Sveriges fångvård och kritiken av fångvården i Finland. Den uttalade målsättningen för denna paradox är att hjälpa fången att klara sig i frihet, men hjälpen visar sig även vara kontroll.

Det är svårt att se, eller ens skönja konturerna av en humanistiskt uformad kontroll, eftersom uppfattningen att fångvården eller straffsystemen under historiens lopp utvecklats i en alltmer human riktning, är en så tilltalande tolkning. Sålunda skapar t.ex. de historiska förändringarna i straffsystemet nästan omärkligt en sådan bild, att straffsystemet hela tiden utvecklas i en alltmer human, bättre och ändamålsenligare riktning. (5) Då Michel Foucault dryftar inställningen till tortyrens avskaffande, träffar han en väsentlig fara i detta tolkningssätt: »kanske det (avskaffande av tortyr) alltför lätt och med alltför högstämda ordalag räknades en viss »humanisering « till godo, varför man ansåg, att det inte fanns skäl att desto närmare analysera denna förändring«. (6)

Med andra ord: När en sak eller förändring förklaras vara »bra«, »human« eller »förändring till det bättre«, behöver man inte längre fundera på den, definiera eller ifrågasätta den. På detta sätt uppstår humana slagord som låter bra, men som till sitt innehåll förblir diffusa, såsom t.ex. »tillgodogörande av strafftiden« eller »rehabilitering«. I allt detta döljer sig faran, att talet om hjälp kamouflerar kontrollen och expansionen av dess användning. På detta sätt kan också personer, som uppriktigt vill göra något gott, i själva verket utan att märka det tjäna en kontroll som blir alltmer förfinad och osynlig.

7. Efter så många påståenden är det kanske skäl att precisera, vad jag inte har påstått. Det är naturligtvis en sak att analysera ett fenomen och en annan sak att acceptera eller fördöma det. Därför bör man inte tolka det jag har sagt så, att jag själv skulle motsätta mig att fångvården utvecklas eller den finländska fångvården kritiseras. Fängelset är ett ställe för mänskligt lidande. Därför är det också nödvändigt att minska på produktionen av pina, och till den i Finland framförda fångvårdskritikens förtjänst bör räknas att denna synpunkt mycket starkt betonats.

Jag har framlagt en hypotes, att fångvården är en kvarn, som producerar fångar och som drivs av sin egen inre konflikt. Den försöker mala mot sig själv: låsa in en människa i fängelse men förhindra de skadeverkningar som förorsakas av frihetsberövandet; förorsaka människorna pina men likväl hjälpa dem att rehabilitera sig. Genom dessa paradoxer misslyckas fångvården med den uppgift, som samhället officiellt värderar, nämligen att förhindra återfallsbrottslighet. Men samtidigt förverkligar den sin dolda samhälleliga uppgift: att producera recidivister.

Om vi inte ens tror på möjligheten av denna grymma mekanism, kan också de som kritiserar fångvården i själva verket bli dess fångar. Det paradoxala i fångvården kamouflerar nämligen och döljer denna mekanism. 
På grund av fångvårdens interna dualism kan man i offentligheten på sätt och vis kritisera den från vardera sidan: såväl från förvaringssäkerhetens som rehabiliteringens sida. Denna möjlighet till kritik från två motsatta håll skymmer fångvårdens uppgift att producera recidivister.

Att dölja denna uppgift betjänas också av, att fångvården mäts med återfallsbrottslighetens nivå. Så länge återfallsbrottsligheten anses vara en mätare på att fångvården misslyckas, kan man kräva antingen mer eller bättre fångvård. Man kan med andra ord låta bli att se, att fångvården lyckas utomordentligt väl med sin samhälleliga uppgift.

Den nordiska diskussionen om fångvården borde inte bygga på illusioner eller på att dölja samhälleliga brutaliteter. Fängelserna är straffanstalter, såväl nu som förr. De grundas ingalunda för att berika fångens levnadslopp. Orsaken till att de upprätthålls grundar sig knappast på så ädla motiv. Att erkänna denna realitet innebär förhoppningsvis också, att man bättre kan påverka den.

\section{Fotnoter:}

1) Helsingin Sanomat 14.6.1987: Vankeinhoito kaipaa elvytystä (Fångvården behöver upplivas).

2) Terttu Utriainen: Turhan paljon vankeja. (Onödigt mycket fångar) Turun Päivälehti 3.9.1987.

3) Raila Taipale: Knowledge and emotions in state's control. Manuskript.

4) Paul van Aerschot: Vankeinhoitouudistus on vietävä loppuun. (Fångvårdsreformen måste slutföras). Helsingin Sanomat 19.5.1987.

5) Tapio Lappi-Seppälä: Teilipyörästä terapiaan. Piirteitä rangaistusjärjestelmän historiasta, s. 168-170. Vankeinhoidon historiaprojektin julkaisu 9/1982. Helsinki 1982 (Från stegelhjul till terapi. Drag ur straffsystemets historia. Fångvårdens historieprojekt, publikation 9/1982).

6) Michel Foucault: Tarkkailla ja rangaista, s. 12. (Kontrollera och bestraffa) Keuruu 1980.

Adress: Docent, specialforskare

Merja-Liisa Hinkkanen-Lievonen

Fångvårdsavdelningen

Justitieministeriet

Postbox 53

SF-00501 Helsingfors 